\title{
LIPIDS ACCUMULATION OF CHLORELLA VULGARIS UNDER VARIABLE LIGHTING CONDITIONS
}

\begin{abstract}
Magdalena ROKICKA, University of Warmia and Mazury in Olsztyn, Faculity of Environmental Sciences, Department of Environmental Engineering, Warszawska St. 117a, 10-719 Olsztyn, magdalena.rokicka@uwm.edu.pl (corresponding author)

Marcin ZIELIŃSKI, University of Warmia and Mazury in Olsztyn, Faculity of Environmental Sciences, Department of Environmental Engineering, Warszawska St.117a, 10-719 Olsztyn, marcin.zielinski@uwm.edu.pl

Marcin DĘBOWSKI, University of Warmia and Mazury in Olsztyn, Faculity of Environmental Sciences, Department of Environmental Engineering, Warszawska St.117a, 10-719 Olsztyn, marcin.debowski@uwm.edu.pl

The cultivation of microalgae is now an intensively developed research area. Some species of microalgae under appropriate conditions accumulate large amounts of lipids in the cells, which may be a suitable feedstock for biodiesel production. The cultures of microalgae for lipids production should be cultivated in specific physicochemical conditions. The most important environmental parameters affecting the algae growth are: nutrients, lighting, reaction, turbulence, salinity and temperature. Periodic changes in lighting is a key parameter that have a significant effect on cells density and lipid accumulation. The mechanism of this action depends on intensity of light and its spectral composition. To produce $3^{\text {rd }}$ and $4^{\text {th }}$ generation biofuels, a better understanding of the relationship between light conditions and yield of lipids accumulation is necessary. The aim of the study was to determine the effects of variable lighting conditions for lipids accumulation of microalgae Chlorella vulgaris and to determine the most effective lighting parameters. The study confirmed the possibility of using the lighting shock conditions to maximize lipids accumulation in algae Chlorella vulgaris cells. In the study, $33.18 \%$ of lipids were obtained from biomass culturing with red light-emitting diodes (LEDs), which was $22 \%$ more than obtained with white continuous lighting.
\end{abstract}

Keywords: microalgae, chlorella vulgaris, photobioreactors, lipids, light, biodiesel

\section{INTRODUCTION}

Combination of technological parameters during microalgae cultivation provides the possibility to stimulate them to produce valuable intracellular metabolites (Freitas, 2017) To maximize the yield of lipids obtained from microalgae biomass for biodiesel production, the biomass should be exposed to unfavorable growth conditions (so-called stress factors). Photosynthesis can be driven by sunlight or artificial light (Wahidin, 2013). Although sunlight is the most costeffective energy source for microalgae production, artificial light has many advantages because of providing better photosynthetic photon flux density, photoperiod and light spectra conditions. These are the most important factors to increase microalgae biomass productivity and quality (Ramanna, 2017). Light requirement is one of the most important parameters and the most expensive factor in mass cultivation of microalgae in photobioreactors (Severes, 2017). Thus, it is substantial to cultivate microalgae with a proper light spectrum and a wavelength range, because they are capable of growing in a narrow bands from the natural light spectrum. The light spectrum for microalgae cultivation is defined as Photosynthetically Active Radiation (PAR), where photosynthesis occurs. PAR region is a radiation between 400-500 nm and 600-700 nm, which corresponds to the visible spectrum and contains $43 \%$ of the solar energy (Ramanna, 2017). The wavelength of solar radiation is very broad and the large amount of light energy is outside the PAR region, remaining unusable. The theoretical maximum value of solar energy conversion into microalgae biomass is estimated to be $13 \%$. However, only less than half of the theoretical value is obtained by using conventional microalgal culture conditions (Ramanna, 2017). Photosynthetic organisms have different intracellular light-harvesting mechanisms that allow them to use only certain wavelengths or a close range of wavelengths even within the PAR region. For this reason, the adaptation or manipulation of light conditions are essential for the effective microalgae cultivation (Seo, 2014).

The intensity of light plays an important role in algal growth, but the light requirements strictly depend on the depth and the density of algae culture. With greater depths and greater biomass concentration, the light intensity should be higher to penetrate the whole culture (Simionato, 2013). The photon flux density and fluctuations in irradiance significantly affected the microalgae biomass density and lipids accumulation in cells. However, that mechanism may

Copyright (C) 2017 The Authors. Published by Aleksandras Stulginskis University. This is an open-access article distributed under the terms of the Creative Commons Attribution License (CC-BY 4.0), which permits unrestricted use, distribution, and reproduction in any medium, provided the original author and source are credited. 
vary considerably and depends on light intensity and its spectral composition. The exposure time, the radiation range and the light intensity determine the productivity of photosynthetic microalga (Zeng,2011).

Excessive intensity of light may lead to photoinhibition, whereas low light levels limits the growth. According to Parmar et al. (2011), changes in light intensity (light and dark photoperiods) determined the microalgae growth rate. Wahidin et al. (2013) found that light, including fluctuations in irradiance, influenced the growth and biochemical composition of microalgae biomass. Metabolism and microalgal growth can be controlled by light intensity or light spectrum (Sodybio, 2017). Depending on the pigment absorption level, microalgal growth is greatly improved by using blue and red light, compared to green (Sudybio, 2017). The duration of an artificial lighting cycle should be at least $18 \mathrm{~h}$ per day, although the microalgae biomass may also develop under a continuous lighting (Levens, 1996). Adjusting the light intensity to the growth phases of algae cultures provided almost $75 \%$ higher biomass productivity (Chen, 2011, Chen,2012). It can also be an effective way to create stress conditions that will promote microalgae to accumulate intracellular metabolites, i.e. lipids. Besides the lipid content in microalgae cells, the fatty acids composition significantly affects the quality of biodiesel production from microalgae biomass. In this way, the quality of biodiesel and its fuel properties depend on the fatty acid methyl ester (FAME) composition, i.e. saturated fatty acids (SFA), monounsaturated fatty acids (MUFAs) and polyunsaturated fatty acids content (PUFAs) (Rai, 2017).

The aim of the study was to determine the potential of Chlorella vulgaris microalgae to lipids accumulation using variable light sources and conditions as the stress factors. The amount of lipids and fatty acids composition were determined depending on the source of light and light exposure times in white, red and blue spectrum. This allowed to identify the most effective cultivation method controlled by shock-induced lighting.

\section{METHODOLOGY}

The taxonomic composition of the inoculum was based on Chlorella vulgaris monoculture. Microalgae cultivation was carried out on a laboratory scale with the use of three vertical, semi-open photobioreactors with an active volume of $2 \mathrm{~L}$. The photobioreactors were placed in a climate cabinet at $20^{\circ} \mathrm{C}$. A supply of $\mathrm{CO}_{2}$ to the bottom of the photobioreactors was ensured by a continuous inflow of air (at $2 \mathrm{~L} / \mathrm{min}$ ), providing appropriate mixing of the cultivation medium and homogeneity of conditions within the entire photobioreactors volume. Microalgae biomass was cultured in a synthetic medium, prepared according to the SAG regulation for Chlorella vulgaris monoculture.

During the study, an initial algae biomass concentration in photobioreactors reached $200 \pm 10 \mathrm{mg}$ DW/L. Hach Lange sensors (Zoitax, Hach Lange) placed in photobioreactors were used for on-line measurements of microalgae biomass concentration. In this study, the microalgae growth rate of the culture for the exponential phase was calculated using the following equation (Kozieł, 2011):

$$
\mu=\frac{\ln \left(N_{2}-N_{1}\right)}{t_{2}-t_{1}}[-]
$$

where: $\mu$ - the specific growth rate, $\mathrm{N}_{1}$ and $\mathrm{N}_{2}$ - the cell densities $(\mathrm{g} / \mathrm{L})$ on days $\mathrm{t}_{1}$ and $\mathrm{t}_{2}$, respectively.

The research organization and construction of research station is shown in Fig. 1.
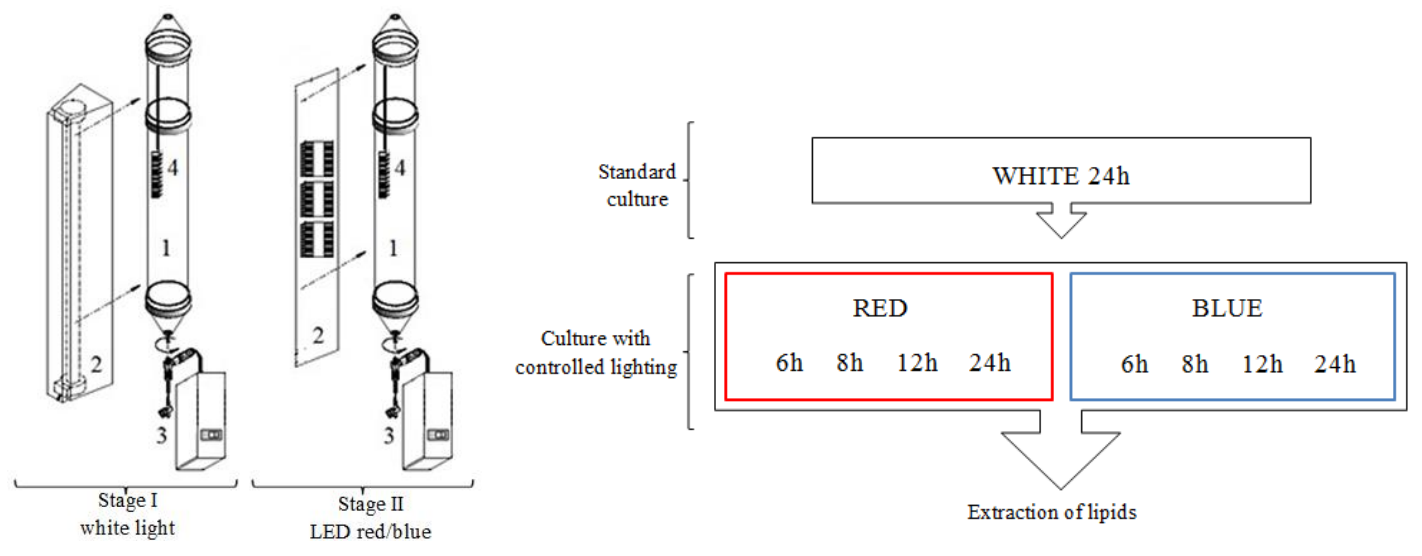

Figure 1. Scheme of the research organization and construction: 1 - vertical photobioreactor, 2 - light source (stage 1 - white light, stage 2 - LEDs), 3 - peristaltic pump, 4 - biomass concentration sensor.

At the first stage, the cultivation of microalgae was conducted without any limitations in technological parameters under continuous white lighting $(1 \mathrm{Klux}, 5600 \mathrm{~K})$ and it lasted for 7 days until the biomass concentration achieved 1200 $\mathrm{mg} \mathrm{DM} / \mathrm{L}$. Microalgae biomass produced at the first stage of experiment was used to inoculate 8 photobioreactors applied in the second stage.

In the second stage, the experiment was performed in 8 variants differed in the source of light used (red LEDs and blue LEDs) and photoperiod cycles (light/dark), (Fig.1). Microalgae biomass was exposed to the variable lighting cycles 
as follow: 6h (60 min light/ $180 \mathrm{~min}$ dark), $8 \mathrm{~h}$ (60 min light/ $120 \mathrm{~min}$ dark), 12h (60 min light/60 min dark) and continuous illumination for $24 \mathrm{~h}$. LEDs used in the experiments were equipped with Helixeon Helio BIO Hyper RED diodes wavelength $660 \mathrm{~nm}$ and Royal BLUE diodes wavelength 440nm. After 7 days of cultivation, microalgae biomass was harvested and concentrated by sedimentation to a volume of $200 \mathrm{~mL}$. The lipids from microalgae cells were extracted using the chloroform/methanol mixture at a ratio of 2:1 (v/v), according to the modified Bligh and Dyer method. After $48 \mathrm{~h}$ of extraction, biomass was centrifuged to remove cell debris and the extract was evaporated on a water bath. The determination of fatty acid methyl esters (FAME) was performed by a gas chromatograph (Bruker 450-GC) equipped with FID detector.

Statistical analysis of results was carried out using the STATISTICA 10.0 PL software package. The hypothesis on the distribution of each analysed variable was verified using the W Shapiro-Wilk test. One-way analysis of variance (ANOVA) was used to determine the significance of differences between variables. The RIR Tukey test was used to determine the significance of differences between the analysed variables. The statistical significance was adopted at $\mathrm{p}=0.05$.

\section{RESULTS AND DISCUSSION}

Light provides energy to support algae growth. However, available radiation must be used with the highest possible efficiency to optimize productivity and make microalgae large scale cultivation energetically and economically sustainable. According to Krzemińska et al. (2015), light intensity is a major environmental factor which influenced the intracellular lipids accumulation and growth rate of $C$. protothecoides. Statistical analysis showed that the light intensity had a significant effect on lipid accumulation in microalgae cells. The total lipids amount on a dry weight basis after extraction was ranged from $24.83 \%$ to $37.53 \%$ under illumination intensities from 35 to $420 \mu$ mol photons $/ \mathrm{m}^{2} \cdot \mathrm{s}$ (Krzeminska, 2015). Thus, the study showed that higher light intensity promoted lipid accumulation in $C$. protothecoides.

In our study, the main objective was to evaluate the effects of lighting exposure time (photoperiod) and wavelength of light emitted by LED light sources on microalgae biomass production and intracellular lipid accumulation in cells. The biomass concentrations in the culture media were shown in Fig. 2. A significant increase in algal biomass concentration in the first stage of the experiment with white continuous lighting was observed. The specific growth rate was 1.11 and the final biomass concentration achieved $1240 \mathrm{mg} \mathrm{DM} / \mathrm{L}$.

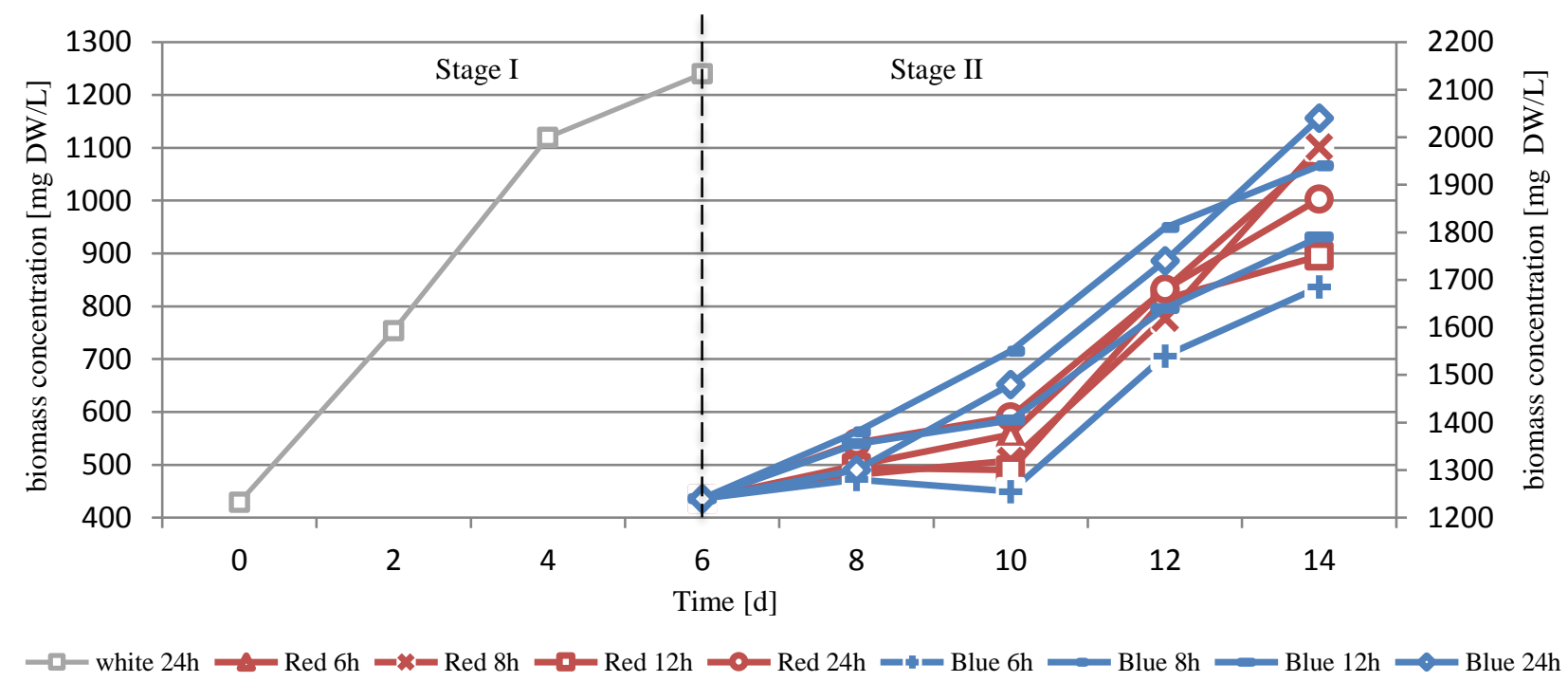

Figure 2. The effect of soure of light and photoperiod lenght on microalgae biomass concentration.

With LED diodes, the concentration of algae biomass successively increased in all tested variants of lighting exposure time. Maximum biomass concentration of $2040 \mathrm{mg} \mathrm{DW} / \mathrm{L}$ was reached when photobioreactor was illuminated continuously for $24 \mathrm{~h}$ with blue diodes, while the lowest biomass producvtivity below $1700 \mathrm{mg} \mathrm{DW} / \mathrm{L}$ was noted with blue diodes and $6 \mathrm{~h}$ of lighting. Red LEDs lighting provided maximum final concentration of biomass on similar level of $1980 \mathrm{mg} \mathrm{DW} / \mathrm{L}$, but at lower lighting exposure time of 8h. An increase in photoperiod lenght to $12 \mathrm{~h}$ was not associated with a higher biomass productivity reached $1750 \mathrm{mg}$ DW/L, which was the lowest in red LEDs lighting variants. The specific growth rate with blue LEDs ranged from 1.01 to 1.11, which was similar to the level of achieved in Red LED lighting variants (1.03 to 1.10). The differences were not stacistically significant ( $p>0.05$ ). Severes et al. (2017) stated, that the use of blue-red LEDs combinations increased only the cell size, but not the culture density. Similar conclusion were drawn by Caner et al. [Levens, 1996], who tested the impact of monochromatic blue light on microalgae biomass productivity. 
Table 1 showed the total lipids yields from microalgae cultivated at different photoperiod cycles and light sources. When applying a continous white lighting, the obtained total lipids amount was $2.79 \mathrm{mg}$ lipids/L of photobioreactor volume, which represented $15 \pm 1.4 \%$ of the volume. The highest total lipids content of $5.76 \mathrm{mg}$ lipids/L (33\%) was obtained when the microalgae cultures were exposed to $12 \mathrm{~h}$ of light with red LEDs. Similar effects $(5.10 \mathrm{mg}$ lipids/L, $28 \%$ ) were obtianed with blue LEDs and the same photoperiod. In all other variants, the amounts of accumulated lipids were on the similar level, thus the differences were not statistically significant $(\mathrm{p}>0.05)$.

These results are comparable to those obtained by Krzemińska et al. (2015), who received the lipid content in $C$. protothecoides ranged from 24.8 to $37.5 \%$. They also stated, that high light intensity significantly promote lipids accumulation in cells. Severes et al. (2017) proposed a two-stage light regime to increase biofuel oil production and improve net lipids yield. First stage of microalgae biomass cultivation was performed at light illuminace of 500 lx with combination of red and blue LEDs. Second phase was the exposition of algae biomass to LEDs of red wavelength (220 lx). This process doubled the lipids yield in comparison to those obtained with white light. In our studies, the two-stage microalgae cultivation allowed 100\% increase of lipids yield (Table 1).

Table 1. Lipids content and composition at different light sources and photoperiod lengths.

\begin{tabular}{|c|c|c|c|c|c|c|c|c|c|}
\hline Light source & White $24 \mathrm{H}$ & Red 6h & Blue $6 \mathrm{~h}$ & Red $8 \mathrm{~h}$ & Blue $8 \mathrm{~h}$ & Red $12 \mathrm{~h}$ & Blue $12 \mathrm{~h}$ & Red 24h & Blue $24 \mathrm{~h}$ \\
\hline Lipid content [\% mass] & $15 \pm 1.4$ & $19 \pm 0.4$ & $22 \pm 0.75$ & $24 \pm 0.2$ & $22 \pm 0.4$ & $33 \pm 1.0$ & $28 \pm 1.8$ & $22 \pm 0.5$ & $19 \pm 0.9$ \\
\hline $\begin{array}{l}\text { Lipids yield [mg/L of } \\
\text { photobioreactor volume] }\end{array}$ & 2.79 & 3.68 & 3.64 & 4.79 & 4.23 & 5.76 & 5.10 & 4.19 & 4.06 \\
\hline $\begin{array}{l}\text { C: } 16 \text { [\% of total fatty } \\
\text { acids] }\end{array}$ & 30.51 & & & & & 31.87 & 30.21 & & \\
\hline $\begin{array}{l}\text { C:18 [\% of total fatty } \\
\text { acids] }\end{array}$ & 10.72 & & & & & 37.33 & 32.54 & & \\
\hline
\end{tabular}

Intracellular triacylglycerols (TAGs) storage in microalgae cells is induced under environmental stress conditions (Hu, 2008, Merchant, 2012). Hayashia et al. (2017) reported that light stress conditions played an important role in increasing TAGs accumulation in Chlorella kessleri cultivated in salty water. They achieved TAGs content increasing from $24.7 \%$ to $48.7 \%$. TAGs are mainly composed of fatty acids with chain lenghts from C16 to C18 (Chen et al., 2012 ; Freitas et al., 2017).

In our study, variable lighting conditions in the two stages of experiment positively affected TAGs accumulation in microalge cells (Table 1). The fatty acids composition in Chlorella vulgaris was as follow: tridecanoic acid (C13: 0), palmitic acid (C16: 0), stearic acid (C18: 0), elaidic acid (C18: 1 TRANS9), gamma-linolenic acid (C18: 3 CIS 6), eicosatrienoic acid (C20: 3 CIS11). The content of C18: 0 acid significantly increased from 10.72\% under white continouos lighting (stage 1) to $34.93 \%$ in varints with red and blue LEDs and the lighting exposure time of $12 \mathrm{~h}$.

Krzemińska et al. (2015) also confirmed that the composition of fatty acids of Chlorella protothecoides is strongly influenced by light intensity. The amount of the C16 -18 fatty acids increased from $76.97 \%$ to $90.24 \%$ of total fatty acids when irradiance was changed from $35 \mu \mathrm{mol}$ photons $/ \mathrm{m}^{2} \cdot \mathrm{s}$ to $420 \mu \mathrm{mol}$ photons $/ \mathrm{m}^{2} \cdot \mathrm{s}$. In the study of Rai and Gupta (2017), the lipids content of Scenedesmus abundans increased up to about $48 \%$ when biomass grown in modified Fogg's medium at $\mathrm{pH} 8$ with light intensity of $40.5 \mu \mathrm{mol}$ photons $/ \mathrm{m}^{2} \cdot \mathrm{s}$ and photoperiod of $16 \mathrm{~h}$ light: $8 \mathrm{~h}$ dark. C16 -18 amounted more than $80 \%$ of the total fatty acids which are considered as the major precursors for biodiesel production.

In biodiesel oil production it is required to use the appropriate microalgae species able to accumulate more lipids with beneficial FAME compositon. There are several microalgae species such as Chlorella, Dunalliella, Nannochlorosis, Nannochloropsis, Neochlorosis, Porphyridium and Scenedesmus, which are promising to be a feedstock for large-scale biodiesel production. However, many further studies should be carried out to make the intracellular lipids accumulation process more technologically and economically effective (Rai, 2017; Kiran, 2014; Mata, 2010).

\section{CONCLUSIONS}

The current commercial production of biodiesel from microalgae still remains economically unprofitable mainly due to the high cost of algae biomass production. To improve the economics of microalgae oil production, the advanced cultivation systems should be developed. Oil production from algal cells of Chlorella vulgaris in respect to the different light sources and photoperiod lengths was evaluated in this work. The study confirmed the possibility of using lighting shock conditions to maximize lipids accumulation by microalgae cells. Maximum total lipids yield of $5.76 \mathrm{mg}$ lipids/L

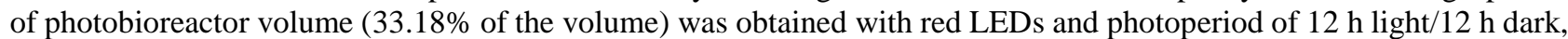
which was $22 \%$ higher than the amount of lipids obtained from biomass cultivated with continuous white illumination. The study indicated that microalgae Chlorella vulgaris cultivated under lighting stress conditions accumulated fatty acids with a suitable composition for biodiesel production. A proper management of light in photobioreactors can improve the efficiency of algae biomass production. However, exploration of the molecular basis of light energy use by microalgae cells will impact implementation of this technology in industrial applications.

\section{ACKNOWLEDGEMENT}

The research was conducted under Project No. 2016/23/N/ST8/03806 from National Science Centre, Poland and was also supported by Project No. 18.620.023-300 from the University of Warmia and Mazury in Olsztyn. 


\section{REFERENCES}

1. Chen, X., Goh, Q. Y., Tan, W., Hossain, I., Chen, W. N., Lau, R. 2011. Lumostatic strategy for microalgae cultivation utilizing image analysis and chlorophyll a content as design parameters. Bioresource technology, 102, vol. 10, pp.6005-6012.

2. Chen, Y. H., Huang, B. Y., Chiang, T. H., Tang, T. C. 2012. Fuel properties of microalgae (Chlorella protothecoides) oil biodiesel and its blends with petroleum diesel. Fuel, Vol. 94, pp. 270-273. https://doi.org/10.1016/j.fuel.2011.11.031

3. Freitas, B. C. B., Cassuriaga, A. P. A., Morais, M. G., Costa, J. A. V. 2017. Pentoses and light intensity increase the growth and carbohydrate production and alter the protein profile of Chlorella minutissima. Bioresource Technology, Vol. 238, pp. $248-253$. https://doi.org/10.1016/j.biortech.2017.04.031

4. Hayashi, T., Otaki, R., Hirai, K., Tsuzuki, M., Sato, N. 2017. Optimization of seawater-based triacylglycerol accumulation in a freshwater green alga, Chlorella kessleri, through simultaneous imposition of lowered-temperature and enhanced-light intensity. Algal Research, vol. 28, pp. 100-107.https://doi.org/10.1016/j.algal.2017.10.016

5. $\mathrm{Hu}$, Q., Sommerfeld, M., Jarvis, E., Ghirardi, M., Posewitz, M., Seibert, M., Darzins, A. 2008. Microalgal triacylglycerols as feedstocks for biofuel production: perspectives and advances. The Plant Journal, Vol. 54, Iss. 4, pp. 621-639.

6. Kiran, B., Kumar, R.,Deshmukh, D. 2014. Perspectives of microalgal biofuels as a renewable source of energy. Energy Conversion and Management, Vol. 88, pp. 1228-1244.https://doi.org/10.1016/j.enconman.2014.06.022

7. Koziel, W., Wlodarczyk, T. 2011. Glony-produkcja biomasy. Acta Agrophysica, 17, vol.1, pp.188.

8. Krzemińska, I., Piasecka, A., Nosalewicz, A., Simionato, D., Wawrzykowski, J. 2015. Alterations of the lipid content and fatty acid profile of Chlorella protothecoides under different light intensities. Bioresource Technology, Vol. 196, pp. 72-77. https://doi.org/10.1016/j.biortech.2015.07.043

9. Levens, P., Sorgeloos, P. 1996. Manual on the production and use of live food for aquaculture (No. 361). Food and Agriculture Organization (FAO)..

10. Mata, T. M., Martins, A. A., Caetano, N. S. 2010. Microalgae for biodiesel production and other applications: a review. Renewable And Sustainable Energy Reviews, Vol. 14, Iss. 1, pp. 217-232.

11. Merchant, S. S., Kropat, J., Liu, B., Shaw, J., Warakanont, J. 2012. TAG, You're it! Chlamydomonas as a reference organism for understanding algal triacylglycerol accumulation. Current Opinion in Biotechnology, Vol. 23, No. 3, pp. 352-363.

12. Parmar, A., Singh, N. K., Pandey, A., Gnansounou, E., Madamwar, D. 2011. Cyanobacteria and microalgae: a positive prospect for biofuels. Bioresource Technology, Vol. 102, Iss. 22, pp. 10163-10172.

13. Rai, M. P., Gupta, S. 2017. Effect of media composition and light supply on biomass, lipid content and FAME profile for quality biofuel production from Scenedesmus abundans. Energy Conversion and Management, Vol. 141, pp. 85-92. https://doi.org/10.1016/j.enconman.2016.05.018

14. Ramanna, L., Rawat, I., Bux, F. 2017. Light enhancement strategies improve microalgal biomass productivity. Renewable and Sustainable Energy Reviews, Vol. 80, pp. 765-773.https://doi.org/10.1016/j.rser.2017.05.202

15. Seo, Y. H., Cho, C., Lee, J. Y., Han, J. I. 2014. Enhancement of growth and lipid production from microalgae using fluorescent paint under the solar radiation. Bioresource Technology, Vol. 173, pp. 193-197. https://doi.org/10.1016/j.biortech.2014.09.012

16. Severes, A., Hegde, S., D'Souza, L., Hegde, S. 2017. Use of light emitting diodes (LEDs) for enhanced lipid production in microalgae based biofuels. Journal of Photochemistry and Photobiology B: Biology, Vol. 170, pp. $235-240$. https://doi.org/10.1016/j.jphotobiol.2017.04.023

17. Simionato, D., Basso, S., Giacometti, G. M., Morosinotto, T. 2013. Optimization of light use efficiency for biofuel production in algae. Biophysical Chemistry, Vol. 182, pp. 71-78. https://doi.org/10.1016/j.bpc.2013.06.017

18. Sudibyo, H., Pradana, Y. S., Samudra, T. T., Budiman, A., Suyono, E. A. 2017. Study of cultivation under different colors of light and growth kinetic study of Chlorella zofingiensis Dönz for biofuel production. Energy Procedia, Vol. 105, pp. $270-276$. https://doi.org/10.1016/j.egypro.2017.03.313

19. Wahidin, S., Idris, A., Shaleh, S. R. M. 2013. The influence of light intensity and photoperiod on the growth and lipid content of microalgae Nannochloropsis sp. Bioresource technology, Vol. 129, pp. 7-11. https://doi.org/10.1016/j.biortech.2012.11.032

20. Zeng, X., Danquah, M. K., Chen, X. D., Lu, Y. 2011. Microalgae bioengineering: from CO 2 fixation to biofuel production. Renewable and Sustainable Energy Reviews, Vol. 15, Iss.6, pp. 3252-3260. 